\title{
Prevalence and Predictors of Mental Health Distress Post-Katrina: Findings From the Gulf Coast Child and Family Health Study
}

\author{
David Abramson, PhD, MPH, Tasha Stehling-Ariza, MPH, \\ Richard Garfield, RN, DrPH, and Irwin Redlener, MD
}

\section{ABSTRACT}

Background: Catastrophic disasters often are associated with massive structural, economic, and population devastation; less understood are the long-term mental health consequences. This study measures the prevalence and predictors of mental health distress and disability of hurricane survivors over an extended period of recovery in a postdisaster setting.

Methods: A representative sample of 1077 displaced or greatly affected households was drawn in 2006 using a stratified cluster sampling of federally subsidized emergency housing settings in Louisiana and Mississippi, and of Mississippi census tracts designated as having experienced major damage from Hurricane Katrina in 2005. Two rounds of data collection were conducted: a baseline face-to-face interview at 6 to 12 months post-Katrina, and a telephone follow-up at 20 to 23 months after the disaster. Mental health disability was measured using the Medical Outcome Study Short Form 12, version 2 mental component summary score. Bivariate and multivariate analyses were conducted examining socioeconomic, demographic, situational, and attitudinal factors associated with mental health distress and disability.

Results: More than half of the cohort at both baseline and follow-up reported significant mental health distress. Self-reported poor health and safety concerns were persistently associated with poorer mental health. Nearly 2 years after the disaster, the greatest predictors of poor mental health included situational characteristics such as greater numbers of children in a household and attitudinal characteristics such as fatalistic sentiments and poor self-efficacy. Informal social support networks were associated significantly with better mental health status. Housing and economic circumstances were not independently associated with poorer mental health.

Conclusions: Mental health distress and disability are pervasive issues among the US Gulf Coast adults and children who experienced long-term displacement or other serious effects as a result of Hurricanes Katrina and Rita. As time progresses postdisaster, social and psychological factors may play greater roles in accelerating or impeding recovery among affected populations. Efforts to expand disaster recovery and preparedness policies to include long-term social re-engagement efforts postdisaster should be considered as a means of reducing mental health sequelae. (Disaster Med Public Health Preparedness. 2008;2:77-86)

Key Words: mental health, social-ecological model, longitudinal cohort, Hurricane Katrina

$\mathrm{D}$ eveloping countries routinely experience mass disasters as a consequence of natural weather events or of social or political conflicts, and the consequences are often compounded by social vulnerabilities and inadequate infrastructure and lifelines. The United States is unaccustomed to dealing with socially seismic events. In particular, disasters that displace large numbers of people or that destroy significant amounts of housing stock or critical infrastructure are relatively rare. The 2005 hurricanes Katrina and Rita represented such rare domestic events. Combined, they affected an area of $108,000 \mathrm{mi}^{2}$, displaced nearly 500,000 people, and exacted an economic cost estimated at more than $\$ 130$ billion. In the aftermath of these hurricanes, several research efforts described the immediate impact of the disaster on affected populations. Virtually all of the field reports noted the incidence of acute mental health problems among survivors of the disaster. ${ }^{1-5}$ Less well understood are the longterm health and psychological effects of the disaster on affected populations. Recent commentators have highlighted the growing concerns surrounding mental health needs subsequent to such natural and manmade disasters. ${ }^{6}$ Scholars have long distinguished between the primary effects of the disaster event itself and the sec- 
ondary effects of postdisaster phenomena such as a population's long-term displacement or the consequences of particular recovery policies and programs. ${ }^{7}$ In the case of the 2005 Gulf Coast storms, the secondary effects included unstable housing, hazardous and crowded housing conditions, loss of social institutions and social networks, and degraded civic infrastructure, particularly among the education, health care, and criminal justice systems. Much of the secondary effect may be attributable to the large-scale population displacement. The Census Bureau projected that as of December 2005 approximately 447,827 individuals had been displaced from the affected areas of Louisiana and Mississippi, among whom were 163,106 children under the age of 18 years. ${ }^{8}$ Of these nearly half-million individuals, approximately 80,000 were placed in transitional housing settings such as group trailer homes or hotels, and an additional 200,000 were given trailers by the US Federal Emergency Management Agency (FEMA), which were placed on their private property. The remaining 170,000 individuals either resettled out of state or found housing in the private market elsewhere in the state. (Transitional housing estimates are based on data from the FEMA Gulf Coast Recovery Office that a total of 21,860 trailers and mobile homes were sited in group settings such as FEMA-developed group sites or preexisting commercial trailer parks in Louisiana and Mississippi, approximately 10,000 units were secured in hotels and motels, and an additional 102,774 trailers and mobile homes were sited on private property. ${ }^{9}$ The population was estimated as 2.5 individuals per group site or hotel room and 2.1 per private site.)

Recent conceptualizations of community resilience in the face of disasters have focused on the capacity of individuals and communities to adapt to and survive major shocks and stresses, ${ }^{10}$ and consistent or improved mental health postdisaster may serve as a marker of such adaptation. Using the Medical Outcome Study Short Form-12 (SF-12) mental health component summary score, this study measured the prevalence of mental health disability among a displaced or heavily affected postdisaster population over 2 points of time, and further examined the factors associated with positive or negative mental health outcomes.

\section{METHODS}

A stratified cluster sampling strategy was used to enroll subjects in the study in 2 phases: the first was used in Louisiana in February 2006, the second in Mississippi in August 2006. Using lists of congregate housing sites obtained from FEMA, we stratified the lists by type of site (FEMA group sites, commercial trailer sites, and hotels) and by size (1-25, 26$50,51-100, \geq 101$ residential units). Congregate sites were selected within each substratum using a probability proportional to size strategy without replacement. Overall, 26 sites were selected as primary sampling units: 12 FEMA group sites, 10 commercial trailer sites, and 4 hotel sites. In addition to sampling the displaced population living in congregate settings, we supplemented the sample frame in Mississippi with an areal sample. Using FEMA damage assessment maps and databases of the state's 3 coastal counties hardest hit by the hurricane, the team randomly selected 150 of 650 census blocks (primary sampling unit clusters) that had been characterized by FEMA as having sustained moderate, extensive, or catastrophic damage. As illustrated in Table 1, 4284 households were sampled as secondary sampling units. Of those, 985 households were deemed ineligible because they were clearly destroyed, vacant, abandoned, or under construction, leaving 3299 eligible households. Among those, 1587 households had an eligible adult present to whom the study was presented; at the remaining 1712 households, no contact was made despite repeated efforts. Among the 1587 contacted households, 1077 agreed to be enrolled in the longitudinal study, corresponding to a response rate of $32.6 \%$ (1077/3299) and a cooperation rate of $67.9 \%$ (1077/1587). A bias analysis was conducted to identify significant differences between respondents who agreed to be studied longitudinally and those who did not. Individuals who did not report their

\section{Sampling Response and Recruitment Rates}

\begin{tabular}{|c|c|c|c|}
\hline & Louisiana & Mississippi & Total \\
\hline No. of sampled households & 1600 & 2684 & 4284 \\
\hline No. ineligible at baseline & 0 & 985 & 985 \\
\hline Total eligible & 1600 & 1699 & 3299 \\
\hline No. of households no response/no contact & 781 & 931 & 1712 \\
\hline No. contacted & 819 & 768 & 1587 \\
\hline No. agreed to follow-up, and interviewed & 553 & 524 & 1077 \\
\hline No. agreed to baseline only, and interviewed & 114 & 56 & 170 \\
\hline No. not available & 41 & 128 & 169 \\
\hline No. refused & 111 & 60 & 171 \\
\hline Response rate for longitudinal study (agreed to follow-up/total eligible), \% & 34.6 & 30.8 & 32.6 \\
\hline Cooperation rate for longitudinal study (total interviewed/contacted), \% & 67.5 & 68.2 & 67.9 \\
\hline Cooperation rate for baseline study (interviewed/contacted), \% & 81.4 & 75.5 & 78.6 \\
\hline Refusal rate (refused/contacted), \% & 13.6 & 7.8 & 10.8 \\
\hline
\end{tabular}


household income and respondents in Louisiana were statistically less likely to agree to be followed up, and individuals with poor mental health scores were more likely to agree to be studied. No other sociodemographic or displacement factors were statistically significant.

An eligible adult respondent was sought at each household sampled who lived at that site and was the "primary caregiver," someone who could knowledgably report on the health issues of all of the individuals in the household. Upon enrollment and completion of the baseline interview, respondents received small gifts for adults and children, valued at approximately $\$ 15$ per household. At follow-up, respondents received a $\$ 30$ gift card. A verbal informed consent was acquired from respondents at each interview round.

At baseline, selected data were collected on all of the household members (eg, age, sex, relationship to respondent, school attendance, chronic health conditions). In addition, a Kish sampling strategy was used to randomly select 1 child in the household for more detailed questions. ${ }^{11}$ Domains of interest included pediatric and adult health status; the prevalence of chronic medical conditions among sampled households; access to health care and services, including health insurance coverage; primary medical, specialty, and dental care needs among sampled children; the prevalence of behavioral conditions and learning disabilities among children; household characteristics such as social and economic resources; social service needs; a brief history of the residents' displacement after the hurricanes; and the demographics of the displaced population. The fol-

low-up survey, conducted between 20 to 23 months after Hurricane Katrina, repeated baseline measures and added measures of social support networks, self-efficacy and locus of control, community engagement (pre- and post-Katrina), and attitudes toward police and criminal justice systems. Among the 1077 respondents eligible for follow-up, 8 had died and 803 were found and interviewed, for a $75.1 \%$ follow-up rate. A bias analysis revealed that the factors most associated with attrition were the absence of a working telephone and having lived at a trailer park that closed down in between the baseline and follow-up interviews. Sociodemographic characteristics such as race/ethnicity, income, age, housing situation, or state of residence were not independently associated with follow-up attrition.

\section{Measures and Analyses}

The outcome variable of mental health disability was measured using the mental component summary score (MCS) derived from the Medical Outcome Study SF-12, version 2, a 12 -item scale that has been validated in both domestic and international populations. ${ }^{12-17}$ The summary mental health score is scored from 0 to 100 (from worst to best mental health) based on 4 subscales measuring vitality, social functioning, role-emotional factors, and mental health, and normed to US population standards such that the population mean is 50 and the standard deviation 10.0. The cutoff score of 42.0 often is used to distinguish psychological distress ( $74 \%$ sensitivity and $81 \%$ specificity in the general US population, ${ }^{17,18}$ although an Australian population study reported a cutoff of 45.0 with $87 \%$ sensitivity and $83 \%$ specificity). ${ }^{19}$ Reliability was high for the SF-12 in both interview rounds, with a Cronbach $\alpha$ of 0.85 in the baseline instrument and 0.91 in the follow-up instrument.

Given that mental health is predicated on internal states and characteristics as well as on interactions between an individual and his or her environment, the independent variables used in the analyses included sociodemographic characteristics such as sex, race/ethnicity, age, partnership status, and the presence of a partner or children in the household; economic characteristics such as income and the presence of a full- or part-time salary earner in the household; housing measures of type of housing and numbers of housing transitions since the hurricane; and attitudinal measures of perceived safety, fatalism, and self-efficacy. Virtually all of the variables used have been identified by Norris et $\mathrm{al}^{20}$ as risk or protective factors for psychological disturbances postdisaster. In addition, a 5-item scale was developed to measure the magnitude of a respondent's functional social support network. Based on Litwak's taskspecific model of social support, ${ }^{21,22}$ which suggests that people seek help for tasks based on the proximity and depth of the social connection and on the specific functional areas associated with that specific task, the items assessed the presence of informal support that involved borrowing money or running errands; taking care of respondents if they were confined to bed for several weeks; lending them several hundred dollars for a medical emergency; counseling them about relationship problems; or helping them locate housing. A principal components factor analysis identified a 1-factor solution with an eigenvalue of 1.693 , in which each of the 5 factors loaded at values ranging from 0.5487 to 0.6583 . The scale's reliability, estimated using Cronbach $\alpha$, was 0.74 .

Several imputations were conducted to address missing items. Items missing at baseline, assumed to be missing completely at random, were imputed using the best-subset regression technique of the Stata 9.2 impute command. Items missing at follow-up were imputed using a system of multiple chained equations, in which 5 imputed datasets were created and then combined for the analyses. 23,24 
The data were examined for intraclass correlation within sampled clusters. A 1-way analysis of variance test of the MCS revealed an intraclass correlation of .008 and no statistically significant differences between clusters $(F=1.30$; $P=.138)$. This supported the sampling strategy assumptions of heterogeneity within clusters. The survey design effect was controlled using the Stata SVY command identifying the cluster sites as primary sampling units. A series of bivariate chi-square analyses and multivariate regressions were conducted to identify the most salient variables associated with mental health, and to test their independent effect. The final regression analyses also controlled for the potentially spurious variable of the respondent's state at enrollment.

\section{RESULTS}

For the purposes of these analyses, 3 distinct subgroups are defined, as illustrated in Table 2: Louisiana respondents, all of whom were still displaced at the point of initial recruitment in the study, living in either group trailer parks or hotels; Mississippi respondents still displaced at baseline, also living in group trailer sites; and community-based Mississippi respondents, some of whom had been displaced after Hurricane Katrina and who had returned home, and of whom others had either experienced only a brief evacuation from their homes.

There were no sex differences among the 3 groups, although there were significant racial differences. The Louisiana displaced population was predominantly African American (75.1\%) in contrast to the displaced group in Mississippi $(36.6 \%)$ and the community-based group (1.6\%). Along other dimensions, the 2 displaced groups were more alike than were the 2 groups within Mississippi. The displaced populations were younger than the community-based group, less likely to be married or living with a partner, and more likely to be living in a household with children. The displaced population in Louisiana was the most economically disadvantaged of the 3 at baseline, in that only $43.7 \%$ of those households had at least 1 salaried wage earner (compared with more than $50 \%$ of households in the Mississippi groups), were the most likely to have household incomes below $\$ 10,000$, and were the likeliest to have lost a salaried wage earner since the hurricanes. The displaced group in Louisiana also reported the greatest number of post-Katrina moves (mean, 3.5) over a shorter period of time (6 months) than did the Mississippi displaced population (a mean of 2.8 moves over a 12 -month period).

\section{TABLE 2}

Sociodemographic Characteristics of Gulf Coast Respondents at Baseline, 2006

\begin{tabular}{|c|c|c|c|c|}
\hline & \multirow[b]{2}{*}{ Louisiana } & \multicolumn{2}{|c|}{ Mississippi } & \multirow[b]{2}{*}{$P$} \\
\hline & & Displaced & Community-based & \\
\hline Total, n & 549 & 333 & 188 & \\
\hline Sex & & & & .921 \\
\hline Female, n (\%) & $326(59.4)$ & $199(59.8)$ & $109(58.0)$ & \\
\hline Male, n (\%) & $223(40.6)$ & $134(40.2)$ & $79(42.0)$ & \\
\hline Race/ethnicity & & & & .000 \\
\hline Black/African American, n (\%) & $412(75.1)$ & $122(36.6)$ & $3(1.6)$ & \\
\hline White, n (\%) & $108(19.7)$ & $180(54.1)$ & $174(92.6)$ & \\
\hline Other, n (\%) & $29(5.3)$ & $31(9.3)$ & $11(5.9)$ & \\
\hline Age, mean (SD) & $45.9(14.4)$ & $44.6(14.8)$ & $51.8(15.1)$ & .000 \\
\hline Partnership status & & & & .000 \\
\hline Married/living with partner, n (\%) & $208(37.9)$ & $142(42.6)$ & $117(62.2)$ & \\
\hline Nonpartnered, n (\%) & $341(62.1)$ & $191(57.4)$ & $71(37.8)$ & \\
\hline Birthplace & & & & .000 \\
\hline Native born, n (\%) & 477 (86.9) & $168(50.5)$ & $49(26.1)$ & \\
\hline Non-native, n (\%) & $72(13.1)$ & $165(49.5)$ & 139 (73.9) & \\
\hline No. of times moved, mean (SD) & $3.5(1.9)$ & $2.9(2.9)$ & $2.8(1.9)$ & .000 \\
\hline Households with children, $\mathrm{n}(\%)$ & $217(39.5)$ & $146(43.8)$ & $60(31.9)$ & .028 \\
\hline No. of children among those households, mean (SD) & $2.0(1.2)$ & $2.2(1.3)$ & $1.7(1.0)$ & .023 \\
\hline Households with salaried wage earner, n (\%) & $240(43.7)$ & $183(55.0)$ & $95(50.5)$ & .004 \\
\hline Annual household income, $\mathrm{n}(\%)$ & & & & .000 \\
\hline$<\$ 10,000$ & $207(37.7)$ & $94(28.2)$ & $21(11.2)$ & \\
\hline$\$ 10,000-\$ 34,999$ & $271(49.4)$ & $187(56.2)$ & $117(62.2)$ & \\
\hline$>\$ 35,000$ & $71(12.9)$ & $52(15.6)$ & $50(26.6)$ & \\
\hline Household salary status since hurricane, n (\%) & & & & .000 \\
\hline Maintained/gained salary & $240(43.7)$ & $183(55.0)$ & $95(50.5)$ & \\
\hline Lost salary & $139(25.3)$ & $60(18.0)$ & 25 (13.3) & \\
\hline Never had salary/not in labor force & $170(31.0)$ & $90(27.0)$ & $68(36.2)$ & \\
\hline
\end{tabular}

Tests for statistical significant were conducted across the 3 groups: chi-square for categorical variables, with Fisher exact test for cells with small $\mathrm{n}$, and $t$ tests for continuous variables. 
Health and Psychosocial Characteristics at Baseline and Follow-up, by State*

\begin{tabular}{|c|c|c|c|c|c|c|}
\hline & \multicolumn{3}{|c|}{ Louisiana } & \multicolumn{3}{|c|}{ Mississippi } \\
\hline & Wave 1 & Wave 2 & $P$ & Wave 1 & Wave 2 & $P$ \\
\hline \multicolumn{7}{|l|}{ Adult health $\dagger$} \\
\hline Self-reported health: excellent, very good, or good, n (\%) & $303(56.6)$ & $317(59.3)$ & .000 & $282(54.9)$ & $303(59.0)$ & .000 \\
\hline Mean physical component score (SD) & $45.3(13.5)$ & $44.5(12.3)$ & $.080 \ddagger$ & 43.9 (13.9) & $42.0(12.5)$ & $.000 \ddagger$ \\
\hline Mean mental component score (SD) & $41.6(13.3)$ & $41.9(11.7)$ & $.648 \ddagger$ & $40.6(13.9)$ & $42.0(12.0)$ & $.011 \ddagger$ \\
\hline Uninsured, $\mathrm{n}(\%)$ & $247(45.0)$ & $154(28.1)$ & .000 & $213(40.9)$ & $168(32.3)$ & .000 \\
\hline Afraid to walk within $1 \mathrm{mi}$ of home at night, $\mathrm{n}(\%)$ & $291(53.0)$ & $334(60.8)$ & .000 & $275(52.8)$ & $287(55.1)$ & .000 \\
\hline \multicolumn{7}{|l|}{ Situation compared to before the hurricane, $\mathrm{n}(\%)$} \\
\hline Worse & & $307(56.3)$ & & & $272(52.3)$ & \\
\hline Same/better & & $75(13.8)$ & & & $81(15.6)$ & \\
\hline Unsure/still changing & & $163(29.9)$ & & & $167(32.1)$ & \\
\hline Mean social support score, scaled 0-1 (SD) & & $0.56(0.30)$ & & & $0.63(0.31)$ & \\
\hline \multicolumn{7}{|l|}{ Civic and social attitudes } \\
\hline $\begin{array}{l}\text { Cynicism: There is not much chance that people will really do } \\
\text { anything to make this a better world, } \mathrm{n}(\%)\end{array}$ & & $171(31.2)$ & & & $167(32.1)$ & \\
\hline $\begin{array}{l}\text { Fatalism 1: Every time I try to get ahead, something or someone } \\
\text { stops me, } n(\%)\end{array}$ & & $291(53.0)$ & & & $277(53.2)$ & \\
\hline $\begin{array}{l}\text { Fatalism 2: People like me don't have a very good chance to be } \\
\text { successful in life, } \mathrm{n}(\%)\end{array}$ & & $81(14.8)$ & & & $82(15.7)$ & \\
\hline $\begin{array}{l}\text { Fatalism 3: For success, good luck is more important than hard } \\
\text { work, } \mathrm{n}(\%)\end{array}$ & & $81(14.8)$ & & & $60(11.5)$ & \\
\hline Self-efficacy: I can handle most things that happen in my life, $\mathrm{n}(\%)$ & & $513(93.4)$ & & & $492(94.4)$ & \\
\hline \multicolumn{7}{|l|}{ Children's health $\dagger$} \\
\hline Parent reported child's health was excellent, very good or good, n (\%) & $336(84.4)$ & $351(88.2)$ & .000 & $370(90.0)$ & $357(86.9)$ & .000 \\
\hline Children with a medical home, $\mathrm{n}(\%)$ & $135(33.9)$ & $257(64.6)$ & .000 & $270(65.7)$ & $277(67.4)$ & .000 \\
\hline Medically uninsured children, n (\%) & $25(6.3)$ & $18(4.5)$ & .000 & $86(20.9)$ & $81(19.7)$ & .000 \\
\hline
\end{tabular}

*Approximately 16 and 10 months passed between the baseline and wave 2 interviews among Louisiana and Mississippi respondents, respectively.

†Adult sample sizes were 548 in Louisiana and 521 in Mississippi, whereas the child sample sizes were 428 in Louisiana and 427 in Mississippi, and child data were weighted by the number of children in the household (missing data was imputed using regression).

$\ddagger$ Statistical significance was determined with a $t$ test analysis.

Physical and mental health characteristics of respondents within each state were compared at baseline and follow-up, as illustrated in Table 3, and psychosocial and environmental characteristics were examined at follow-up only. Measures of global self-reported health improved significantly in both states from baseline interview to follow-up, as did the mean MCS in Mississippi. The mental health scores in Louisiana remained stable at both baseline and follow-up. The proportion of adult uninsured respondents dropped significantly in each state, decreasing from $45.0 \%$ to $26.6 \%$ in Louisiana and from $40.9 \%$ to $31.5 \%$ in Mississippi.

More than half of the respondents in both states were afraid to walk alone at night in their neighborhood when first interviewed (53.0\% and 52.8\% in Louisiana and Mississippi, respectively), and those proportions rose significantly in both states at follow-up. When asked to characterize their situation almost 2 years after the hurricanes, more than half of the respondents in both states said circumstances were worse and nearly one third said they were still too unsettled to determine whether their situation was better or worse. However, a number of items revealed functional informal social support networks and, often, a strong sense of self-efficacy and locus of control.
Comparing the mental health scores by various markers of social and economic advantage among the 3 groups suggests that a number of factors may mediate the impact of postKatrina displacement on mental health. Table 4 depicts a series of analysis of variance tests in which the mean MCS at follow-up was compared across the 3 population groups within distinct categorical values. Economic advantages, such as having a higher income and not having lost a salaried wage earner in the household, were associated with a higher mental health score. Conversely, adults who described greater household and environmental stressors (eg, living in a group trailer site, living in an unsafe neighborhood, moving 4 or more times since the hurricanes and still being displaced, having 3 or more children in the household) also reported lower mental health scores. Individuals reporting greater adaptive or coping resources, such as strong functional support networks or higher degrees of self-efficacy, tended to score higher on the mental health scale.

The combined effects of these potential factors were tested in a series of regression analyses, illustrated in Table 5. In the first analysis, the mental health score at baseline was regressed on sociodemographic characteristics. A second regression replicated that model at follow-up. A final expanded 


\section{TABLE 4}

\section{Mental Health Distress and Disability at Follow-up: Mean Mental Component Summary Score (MCS),} by State

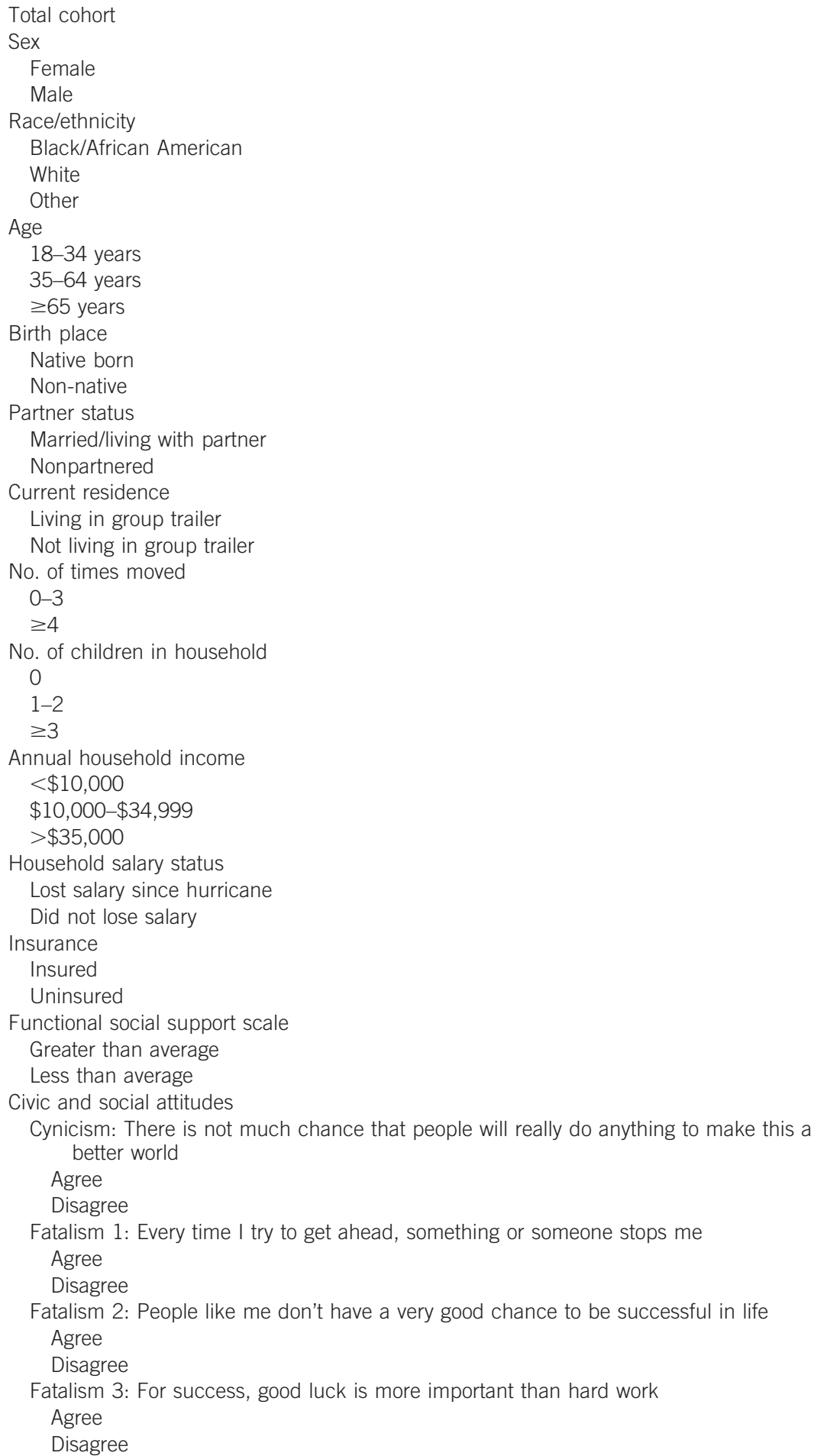

\begin{tabular}{|c|c|c|c|}
\hline \multirow[b]{2}{*}{ Louisiana } & \multicolumn{2}{|c|}{ Mississippi } & \multirow[b]{3}{*}{$P$} \\
\hline & & Remained in & \\
\hline Displaced & Displaced & Community & \\
\hline 41.9 (11.7) & $40.8(11.5)$ & $44.2(12.6)$ & .007 \\
\hline $41.2(12.0)$ & 39.2 (11.3) & $42.3(13.2)$ & .063 \\
\hline $42.9(11.1)$ & $43.3(11.2)$ & $46.8(11.3)$ & .022 \\
\hline $42.2(11.5)$ & $42.9(11.0)$ & * & .541 \\
\hline $40.8(12.7)$ & 39.6 (11.6) & 44.5 (12.5) & .001 \\
\hline $41.1(10.4)$ & $40.0(11.1)$ & 36.6 (12.9) & .521 \\
\hline 41.4 (10.9) & $42.1(10.5)$ & $45.9(8.9)$ & .211 \\
\hline $41.6(12.1)$ & 39.9 (11.8) & $42.9(12.9)$ & .074 \\
\hline $44.0(10.5)$ & $43.5(10.8)$ & 46.5 (13.0) & .354 \\
\hline 41.9 (11.5) & $41.3(10.8)$ & $43.2(13.0)$ & .609 \\
\hline 41.5 (12.8) & $40.3(12.0)$ & $44.6(12.4)$ & .011 \\
\hline 43.54 (11.8) & 40.6 (11.5) & $45.6(12.2)$ & .004 \\
\hline 41.1 (11.6) & $41.0(11.4)$ & $42.2(13.0)$ & .704 \\
\hline $41.0(10.8)$ & 40.3 (11.4) & * & .467 \\
\hline $42.9(12.6)$ & $42.3(11.4)$ & $44.2(12.7)$ & .415 \\
\hline $43.3(11.5)$ & $42.0(11.0)$ & 43.9 (13.4) & .294 \\
\hline 41.2 (11.7) & 38.6 (11.9) & $44.6(11.4)$ & .003 \\
\hline 42.8 (11.9) & 41.9 (11.5) & $43.9(13.1)$ & .336 \\
\hline 41.7 (10.9) & $40.6(11.7)$ & $46.2(11.1)$ & .019 \\
\hline 37.7 (11.7) & $37.8(9.9)$ & $40.7(11.7)$ & 618 \\
\hline 40.2 (12.3) & $39.1(12.5)$ & 38.3 (12.3) & .581 \\
\hline $42.2(10.8)$ & 40.9 (11.0) & $43.3(12.3)$ & .319 \\
\hline $42.9(10.5)$ & $42.4(10.2)$ & $45.6(13.1)$ & .346 \\
\hline $37.2(11.8)$ & $40.0(11.1)$ & 39.6 (11.9) & .502 \\
\hline $42.5(11.5)$ & 40.9 (11.5) & $44.5(12.6)$ & .005 \\
\hline $42.2(11.1)$ & $41.6(10.6)$ & $44.2(13.5)$ & .143 \\
\hline 40.9 (13.1) & 38.8 (13.1) & $44.2(11.2)$ & .020 \\
\hline $44.7(10.5)$ & $43.5(10.1)$ & $45.6(12.2)$ & .172 \\
\hline $38.2(12.1)$ & 35.4 (12.1) & $40.6(12.8)$ & .025 \\
\hline 39.6 (12.7) & $39.2(12.2)$ & $43.1(15.1)$ & .150 \\
\hline $42.9(11.0)$ & 41.7 (10.9) & $44.7(11.4)$ & .046 \\
\hline $37.8(11.0)$ & $38.8(10.8)$ & $41.0(13.7)$ & .080 \\
\hline $46.5(10.7)$ & 43.7 (11.7) & 46.7 (11.1) & .043 \\
\hline 37.1 (12.1) & 34.2 (12.0) & $34.6(13.4)$ & .374 \\
\hline 42.7 (11.4) & $42.0(10.9)$ & $46.2(11.5)$ & .001 \\
\hline 39.7 (12.2) & 41.7 (12.6) & $37.9(13.5)$ & .517 \\
\hline 42.2 (11.6) & 40.7 (11.3) & 44.9 (12.3) & $\begin{array}{c}.001 \\
\text { (Continued) }\end{array}$ \\
\hline
\end{tabular}


Mental Health Distress and Disability at Follow-up: Mean Mental Component Summary Score (MCS), by State (Continued)

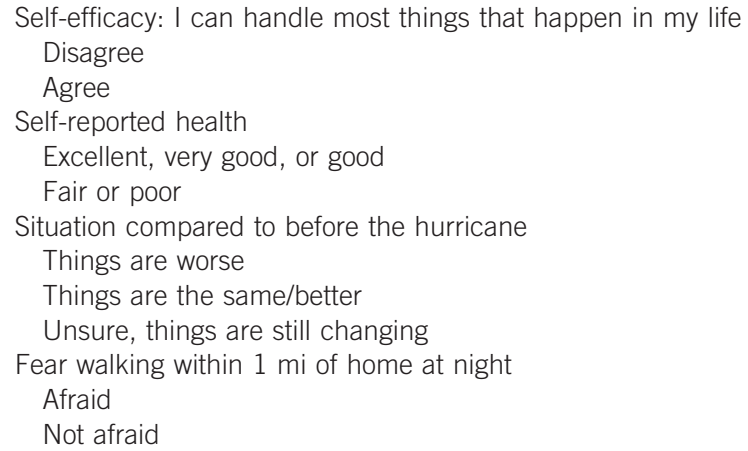

Self-efficacy: I can handle most things that happen in my life
Disagree
Agree
Self-reported health
Excellent, very good, or good
Fair or poor
Situation compared to before the hurricane
Things are worse
Things are the same/better
Unsure, things are still changing
Fear walking within 1 mi of home at night
Afraid
Not afraid

Standard deviations are reported within the parentheses.

${ }^{*}$ Cells with $<10$ respondents were excluded from analysis.

\section{TABIE 5}

\section{Multivariate Regression Models of Factors Associated With Higher Adult Mental Health Scores}

Sex: male

Race/ethnicity: Black/African American

Age

Partnered (married or living with partner)

Living in Louisiana

Native born

Living in group trailer at interview

No. of times moved

No. of children in household

Household lost salary income after hurricane

Annual household income

$<\$ 10,000$

$\$ 10,000-\$ 34,999$

$>\$ 35,000$

Worsening self-reported health

Uninsured

Afraid in community

MCS at previous wave

Recovery: things are the same or better since Katrina

Functional social support scale

Civic and social attitudes

Cynicism: There is not much chance that people will really do anything to make this a better world

Fatalism 1: Every time I try to get ahead, something or someone stops me

Fatalism 2: People like me don't have a very good chance to be successful in life

Fatalism 3: For success, good luck is more important than hard work

Self-efficacy: I can handle most things that happen in my life

\begin{tabular}{rrc}
\multicolumn{3}{c}{ Baseline } \\
\hline $\boldsymbol{\beta}$ & SE & $\boldsymbol{P}$ \\
2.12 & .76 & .009 \\
.07 & 1.06 & .945 \\
.12 & .03 & .000 \\
1.45 & .78 & .074 \\
2.08 & 1.04 & .054 \\
-1.18 & 1.01 & .256 \\
.56 & 1.12 & .622 \\
-.32 & .21 & .131 \\
.12 & .30 & .695 \\
-2.26 & 1.27 & .087 \\
& & \\
.00 & - & - \\
-.18 & 1.01 & .861 \\
.35 & 1.59 & .825 \\
-3.19 & .33 & .000 \\
.45 & .93 & .630 \\
-3.70 & .85 & .000
\end{tabular}

\begin{tabular}{rrr}
\multicolumn{3}{c}{$\begin{array}{r}\text { Wave 2 Replicated } \\
\text { Baseline Model }\end{array}$} \\
\hline \multicolumn{1}{c}{$\boldsymbol{\beta}$} & \multicolumn{1}{c}{ SE } & $\boldsymbol{P}$ \\
.43 & .93 & .649 \\
1.36 & 1.05 & .209 \\
.07 & .03 & .032 \\
1.54 & .95 & .110 \\
-.12 & 1.14 & .917 \\
.29 & 1.04 & .780 \\
-.51 & .94 & .588 \\
-.48 & .22 & .031 \\
-1.00 & .37 & .008 \\
-2.12 & 1.42 & .146 \\
& & \\
.00 & - & - \\
1.28 & .97 & .188 \\
2.57 & 1.54 & .098 \\
-3.64 & .36 & .000 \\
-.78 & .91 & .394 \\
-3.22 & .88 & .000
\end{tabular}

40.9 (11.4)

$40.0(11.9)$

$44.4(10.3)$

$35.3(10.8)$

$39.0(10.3)$

$52.1(9.4)$

40.9 (12.2)

$39.2(11.0)$

43.2 (11.6)
Mississippi

Remained in Community

$44.7(12.2)$ 
regression model repeated those measures and added the psychosocial factors measured at follow-up. At baseline, men and older respondents were more likely to report better mental health than were women or younger respondents. Individuals reporting poor physical health and those who believed that they lived in unsafe neighborhoods also were more likely to report poorer mental health, all other factors being equal. When the same model was run at follow-up, increasing age was still associated with better mental health and poor physical health and unsafe neighborhoods were still associated with poorer mental health. Sex, however, was no longer statistically significant, and other factors emerged as statistically significant: respondents who had moved often and those who had a greater number of children in the household were more likely to have poorer mental health. There were no differences by state, by whether a respondent was living in a trailer at the time of the interview, or by economic factors. In the final expanded regression model, 2 of the factors that had been significant in the reduced baseline model, age and the number of times that someone moved, were no longer significant. Other factors emerged that were associated with better mental health scores: a respondent's positive state of mind (reflected by an absence of fatalist attitudes) and sense of self-efficacy, the presence of a functional social support network, and better mental health at baseline.

\section{DISCUSSION}

Our findings suggest that mental health distress and disability continue to have an impact on a number of adults who were displaced or greatly affected by the hurricanes, even as they move back to their communities. The measure of mental health we used, the MCS, is significantly lower at both baseline and follow-up than US population means, and the average change between baseline and follow-up (1.52) is significantly lower than the norm for 1 -year change scores among individuals with clinical depression (3.86). ${ }^{18}$ Some of the predictors of mental health disability also changed over time. Whereas women and Louisiana respondents had poorer mental health at baseline, these differences receded at followup. The measure of continued transience and uncertainty, the number of times an individual moved residences, became a significant independent factor associated with poorer mental health. Perhaps more telling is that in the expanded regression model, structural and economic factors such as living in a trailer and losing a salaried wage earner in the household are not associated with poorer mental health, but are subsumed by social factors such as a strong or weak informal network and underlying attitudes of fatalism or self-efficacy.
Resilience is the product of both individual and social factors, and our study data suggest that elements at both levels contribute to successful adaptation to prolonged stress. The continued association of perceived insecurity and poor mental health, at both baseline and follow-up, highlights 1 potential neighborhood effect that impedes recovery. Although some markers of population recovery are evident, such as increases in self-reported physical health and improved access to health insurance for some children in Louisiana, there are clearly other structural, social, and psychological factors that impede recovery. The context of the lives of these survivors-all of whom have either experienced a prolonged displacement or whose communities and social fabric have been fundamentally altered - is bracketed by uncertainty about their future, severe constraints on their current circumstances, and often a history of social marginalization or disenfranchisement.

An international standard for addressing the mental and social aspects of health subsequent to large-scale disasters, the Sphere protocol, has evolved recently. ${ }^{25,26}$ The Sphere model recommends the rapid provision of such social reengagement activities as the reestablishment of religious events and institutions and the resumption of formal education and appropriate recreational activities for children to speed recovery. Silove et al have proposed a similar theoretical framework encompassing the recovery of individuals and collectives, known as the adaptation and development after persecution and trauma (ADAPT) model. 27 The model enumerates key psychosocial domains threatened by a disaster: safety and security, interpersonal networks, systems of justice, social identities and roles, and institutions that confer meaning and coherence (eg, those imparted by religious institutions and practices, political and social engagement). Taken together, these socioecological frameworks suggest that a stronger social web that incorporates elements of security and resumption of social roles, social practices, and social institutions can provide a therapeutic effect. The preliminary findings reported in our study provide some supporting evidence for such socioecological frameworks.

There are clear limitations to our study. Pre-Katrina data on mental health status were unavailable, so it is unknown whether displaced or heavily affected populations experienced preexisting mental health conditions. In Louisiana, the study sample was restricted to individuals displaced in federally subsidized settings, and thus the findings cannot be generalized to other affected populations. Initial response rates were low, a consequence of the challenges of conduct- 
ing research operations in a postdisaster setting in which it was not possible to distinguish eligible households from vacant or abandoned ones. The fluid nature of the displaced population's transience also made follow-up efforts particularly difficult, opening a potential bias between those who could be located and those who could not. Finally, we focused on populations displaced within their home state, and did not recruit households that had been displaced (or permanently relocated) to other states. A number of our respondents had been placed in transitional housing in other states, but by the time of study enrollment had returned to their home state. It is unknown to us whether there are significant differences between these in-state and out-of-state populations. Despite these limitations, the value of such a longitudinal study is that it permits analyses of change over time, which we believe is particularly critical to advancing an understanding of the arc of recovery in a postdisaster setting.

\section{Policy Implications}

Within the realm of disaster recovery, US policy has focused principally on the recovery of place rather than the recovery of person. ${ }^{28,29}$ Although the research community has examined the impact of disasters on individuals, the focus has often been time limited; more than two thirds of US disaster studies have been cross-sectional, conducted within the first year postdisaster, and it is the rare study that studies subjects beyond one follow-up point of data collection. ${ }^{20}$ Furthermore, these disaster studies usually examine psychopathological states among disaster victims, such as posttraumatic stress disorder, depression and anxiety, or psychosomatic disorders. ${ }^{30-32}$ Among the consequences of these foci of federal policy and disaster mental health research have been that interventions intended for disaster victims generally have been constrained by an economic model of redress (housing resettlement, short-term aid) and clinical and subclinical efforts to address short-term health effects, such as a reliance upon psychological "first aid," stress debriefing, and cognitive-behavioral therapies. Efforts to expand disaster recovery and preparedness policies to include social reengagement efforts postdisaster should be considered as a means of reducing mental health sequelae and as a strategy for accelerating recovery for affected populations. ${ }^{33}$

\section{About the Authors}

Dr Abramson is the Director of Research, Ms Stehling-Ariza is a research associate, and Dr Redlener is the Director of the National Center for Disaster Preparedness, Columbia University Mailman School of Public Health; Dr Garfield is the Henrik H. Bendixen Professor of Clinical International Nursing in the Columbia University School of Nursing.

As principal investigator, Dr Abramson was the primary author, and led the study's design and analysis. Ms Stehling-Ariza was the project director and research analyst responsible for data analyses. Dr Garfield was co-principal investigator and the primary editor. Dr Redlener reviewed and edited the manuscript.

Address correspondence and reprint requests to David Abramson, PhD, MPH, National Center for Disaster Preparedness, Columbia University Mailman School of Public Health, 722 W 168th St, Room 1014, New York, NY 10032 (e-mail: dma3@columbia.edu).
Received for publication February 28, 2008; accepted March 12, 2008.

ISSN: $1935-7893$ C 2008 by the American Medical Association and Lippincott Williams \& Wilkins.

\section{DOI: 10.1097/DMP.0b013e318173a8e7}

\section{Authors' Disclosures}

The authors report no conflicts of interest.

\section{Acknowledgments}

This research adheres to the Public Health Code of Ethics. It was covered by protocol AAAB-8668, and reviewed and approved by the Columbia University Medical Center institutional review board. Respondents provided verbal informed consent, and received compensation for their participation in the study.

This research was funded by The Children's Health Fund as part of its Operation Assist program, awarded to Columbia University's National Center for Disaster Preparedness. Special thanks to Barbara Bennet, MPH, and M. Catherine Trimbur, MPH, who served as field directors during the data collection efforts, and to Stephanie Tortu, PhD (Louisiana State University); Linda Southward, PhD (Mississippi State University); and Erin Brewer, MD, MPH (Louisiana Department of Health and Hospitals) for considerable guidance and support throughout the field operations.

\section{REFERENCES}

1. Brodie M, Weltzien E, Altman D, et al. Experiences of hurricane Katrina evacuees in Houston shelters: implications for future planning. Am J Public Health. 2006;96:1402-1408.

2. Weisler RH, Barbee JG, Townsend MH. Mental health and recovery in the Gulf Coast after Hurricanes Katrina and Rita. JAMA. 2006;296: $585-588$.

3. Kessler RC. Hurricane Katrina's impact on the care of survivors with chronic medical conditions. J Gen Intern Med. 2007;22:1225-1230.

4. Kessler RC, Galea S, Jones RT, Parker HA. Mental illness and suicidality after Hurricane Katrina. Bull WHO. 2006;84:930-939.

5. Wang PS, Gruber MJ, Powers RE, et al. Mental health service use among Hurricane Katrina survivors in the eight months after the disaster. Psychiatr Serv. 2007;58:1403-1411.

6. Satcher D, Friel S, Bell R. Natural and manmade disasters and mental health. JAMA. 2007;298:2540-2542.

7. Quarantelli EL. The Disaster Research Center (DRC) field studies of organized behavior in the crisis time period of disasters. In: Stallings RA, ed. Methods of Disaster Research. Philadelphia: XLibris; 2002.

8. US Census Bureau. 2005 Gulf Coast area data profiles. American community survey. http://www.census.gov/acs/www/Products/Profiles/gulf_ coast/profiles.htm. Accessed February 28, 2008.

9. Federal Emergency Management Agency. Individual assistance program global report, Vol. 28. February 15, 2008. http://www.fema.gov/hazard/ hurricane/2005katrina/weekly_ia.shtm. Accessed February 28, 2008.

10. Manyena SB. The concept of resilience revisited. Disasters. 2006;30: 433-450.

11. Kish L. Survey Sampling. New York: J. Wiley; 1965.

12. Amir M, Lewin-Epstein N, Becker G, Buskila D. Psychometric properties of the SF-12 (Hebrew version) in a primary care population in Israel. Med Care. 2002;40:918-928.

13. Fleishman JA, Zuvekas SH. Global self-rated mental health: associations with other mental health measures and with role functioning. Med Care. 2007;45:602-609.

14. Van Griensven F, Chakkraband ML, Thienkrua W et al. Mental health problems among adults in tsunami-affected areas in southern Thailand. JAMA. 2006;296:537-548.

15. Ware JE. Improvements in short-form measures of health status: introduction to a series. J Clin Epidemiol. 2008;61:1-5.

16. Ware JE, Gandek B, Aaronson N et al. Testing the SF-12 summary 
health measures in nine countries: results from the IQOLA Project. Qual Life Res. 1997;6:417-417.

17. Ware JE, Kosinski M, Keller SD. A 12-item short-form health surveyconstruction of scales and preliminary tests of reliability and validity. Med Care. 1996;34:220-233.

18. Ware JE, Kosinski M, Keller SD. SF-36 Physical Eु Mental Health Summary Scales: A User's Manual. 5th ed. Lincoln, RI: QualityMetric; 1994.

19. Gill SC, Butterworth P, Rodgers B, Mackinnon A. Validity of the mental health component scale of the 12-item Short-Form Health Survey (MCS-12) as measure of common mental disorders in the general population. Psychiatry Res. 2007;152:63-71.

20. Norris FH, Friedman MJ, Watson PJ, et al. 60,000 disaster victims speak: I. An empirical review of the empirical literature, 1981-2001. Psychiatry. 2002;65:207-239.

21. Litwak E, Messeri P, Wolfe S, et al. Organizational theory, social supports, and mortality rates—a theoretical convergence. Am Sociol Rev. 1989;54:49-66.

22. Messeri P, Silverstein M, Litwak E. Choosing optimal support groups-a review and reformulation. J Health Soc Behav. 1993;34:122-137.

23. Royston P. Multiple imputation of missing values: update. Stata J. 2005;5:188-201.

24. Schafer JL. Multiple imputation: a primer. Stat Methods Med Res. 1999; 8:3-15.
25. Morris J, van Ommeren M, Belfer M, et al. Children and the Sphere standard on mental and social aspects of health. Disasters. 2007;31: 71-90.

26. Project Sphere. Humanitarian Charter and Minimum Standards in Disaster Response. Oxford, UK: Oxfam Publishing; 2004.

27. Silove D, Steel Z, Psychol M. Understanding community psychosocial needs after disasters: implications for mental health services. J Postgrad Med. 2006;52:121-125.

28. May PJ. Recovering From Catastrophes: Federal Disaster Relief Policy and Politics. Westport, CT: Greenwood Press; 1985.

29. Platt RH. Disasters and Democracy: The Politics of Extreme Natural Events. Washington, DC: Island Press; 1999.

30. Norris FH, Murphy AD, Baker CK, Perilla JL. Postdisaster PTSD over four waves of a panel study of Mexico's 1999 flood. J Trauma Stress. 2004;17:283-292.

31. Galea S, Nandi A, Vlahov D. The epidemiology of post-traumatic stress disorder after disasters. Epidemiol Rev. 2005;27:78-91.

32. Shaw JA, Applegate B, Schorr C. Twenty-one-month follow-up study of school-age children exposed to Hurricane Andrew. J Am Acad Child Adolesc Psychiatry. 1996;35:359-364.

33. Van Ommeren M, Saxena S, Saraceno B. Aid after disasters. BMJ. 2005;330:1160-1161. 